\title{
LOW PREVALENCE OF AN ACUTE PHASE RESPONSE IN ASYMPTOMATIC CHILDREN FROM A MALARIA-ENDEMIC AREA OF PAPUA NEW GUINEA
}

\author{
HEATHER IMRIE,t FREYA J. I. FOWKES,t PASCAL MICHON, LIVINGSTONE TAVUL, JOHN C. REEDER, AND
}

KAREN P. DAY*

Peter Medawar Building for Pathogen Research and Department of Zoology, University of Oxford, Oxford, United Kingdom; Papua New Guinea Institute of Medical Research, Madang, Papua New Guinea; Papua New Guinea Institute of Medical Research, Goroka, Papua New Guinea; Department of Medical Parasitology, New York University School of Medicine, New York

\begin{abstract}
Levels of C-reactive protein (CRP), a classic marker for the acute phase response (APR), were measured in children with asymptomatic malaria infection in the Amele region of Papua New Guinea (PNG). Despite the presence of parasitemia, the prevalence of CRP levels consistent with an APR (CRP > 10 (xg/mL) was very low $(<10 \%)$. Splenomegaly was significantly associated with increased parasitemia $(P<0.001)$ and CRP levels $(P<0.001)$, highlighting the importance of splenomegaly as an indicator of recent high density infection in this population. Multivariate analysis showed that CRP levels were significantly associated with splenomegaly, fever, hemoglobin, and age $(P<$ 0.002). CRP levels also increased with increasing parasitemia $(P<0.001)$ but remained $<3.5$ (xg/mL. The low levels of CRP indicate that children in the Amele modulate inflammation associated with malaria.
\end{abstract}

\section{INTRODUCTION}

Acute phase proteins (APPs) are serum proteins, the concentrations of which change during the acute phase response (APR) to a variety of stimuli, such as infection and other inflammatory reactions. APPs are predominantly synthesized by the liver with interleukin (IL)- 6 as the principal cytokine inducing production. ${ }^{1}$ IL-1, IL-8, tumor necrosis factor-a, interferon^, leukemia inhibitory factor, and transforming growth factor-( 3 can also regulate APP production. ${ }^{1}$ APPs are classified on the basis of how they change during the APR. Proteins that decrease are classified as negative APPs, whereas proteins that increase are classified as positive APPs. Albumin is a negative APP because its synthesis is significantly reduced by IL-6 during the APR. ${ }^{2}$ Positive APPs include $\mathrm{C}$-reactive protein $(\mathrm{CRP}), \mathrm{o}^{\wedge}$-antitrypsin, ferritin, and haptoglobin $(\mathrm{Hp})$. During acute inflammation, CRP concentrations increase 100 - to 1,000 -fold, whereas $\mathrm{o}^{\wedge}$-antitrypsin, ferritin, and $\mathrm{Hp}$ concentrations increase 2- to 4-fold during an APR. ${ }^{1}$ CRP is therefore a classic marker for inflammation, and an APR is often defined as CRP > $10\left(\mathrm{xg} / \mathrm{mL}{ }^{1{ }^{1,2}}\right.$

When malaria schizonts rupture, host monocytes and macrophages secrete pro-inflammatory cytokines stimulating the production of CRP. ${ }^{3,4}$ Strong correlations between CRP and malaria parasitemia have been shown, even in afebrile individuals. ${ }^{\mathrm{s}} \sim{ }^{8}$ Previous studies in African populations show that children in malaria-endemic areas have a chronic inflammatory response to continued and prolonged exposure to Plasmodium infections as evidenced by the high prevalences of APR. ${ }^{9-12}$ The APR has not been studied in malaria-endemic communities outside Africa. Consequently, we measured concentrations of CRP, $\mathrm{o}^{\wedge}$-antitrypsin, and albumin in a cohort of children living in the north coastal region of Papua New Guinea (PNG). Children living in this area harbor chronic, asymptomatic malaria infections with clinical episodes associated with fever, high parasitemia, and splenomegaly. ${ }^{13,14}$ We examined the relationship of the above-mentioned APPs with demographics, malariometric indices, and host polymor-

* Address correspondence to Karen Day, Department of Medical Parasitology, New York University School of Medicine, 341 East 25th Street, New York, NY 10010. E-mail: karen.day@med.nyu.edu

$\dagger$ These authors contributed equally to the work. phisms in a cohort of children from the Amele region, PNG, where we have previously reported concentrations of the APP Hp. ${ }^{15}$

\section{MATERIALS AND METHODS}

Study site. The study was conducted in villages of the north coastal Amele region of PNG where malaria transmission is intense. ${ }^{16}$ The region has a tropical climate with high annual rainfall and year round malaria transmission, with a peak recognized between October and May. The EIR ( $P$. falciparum and $P$. vivax) in this region is estimated at 0.86 infective bite/person/night. ${ }^{17}$ Semi-immune children $>4$ years of age from Amele harbor chronic, asymptomatic malaria infections of $P$. falciparum, $P$. vivax, $P$. malariae, and $P$. ovale, with occasional episodes of clinical malaria associated with splenomegaly, fever, and parasitemia above the fever threshold of 1,000 parasites/jxA. ${ }^{13,14}$ Young children $<4$ years of age have more frequent clinical episodes of malaria associated with high parasite densities. ${ }^{14}$

$\mathrm{ot}^{+}-$Thalassemia reaches very high frequencies in the Amele region, and polymorphisms such as Southeast Asian ovalocytosis (SAO) and glucose 6-phosphate dehydrogenase (G6PD) deficiency are also present in this area. ${ }^{18-20}$

Study design and data collection. A serial cross-sectional survey was conducted in a cohort of children (1-17 years of age in 1999) from November to December of 1999 and 2000. This study was initially designed to examine Hp levels with respect to host genotype in the Amele community, details and results of which have been published previously. ${ }^{21} \mathrm{We}$ studied these children further in relation to the APR in relation to host genotype. The dynamics of APP during the APR are such that data from a single time-point may be difficult to interpret. A serial study design would ensure that any associations observed with host genotype would be less likely to have occurred by chance. Therefore, archived samples from this previous study were deemed suitable for this retrospective analysis of APP. Sufficient samples for APP determination remained for 394 individuals in 1999 and 466 individuals in 2000 (343 pairs). $\mathbf{0}^{\wedge}$-Antitrypsin concentrations were determined in samples collected in 1999 only.

Axiliary temperatures were recorded for each child, and fever was defined as a temperature $>37.5^{\circ} \mathrm{C}$ Examination 
for splenomegaly was conducted using the Hackett grading system. Venous blood was drawn using Vacutainer tubes (Becton Dickinson, Oxford, UK) containing EDTA as an anti-coagulant. A blood smear was immediately made and later stained with Giemsa. Levels of hemoglobin $(\mathrm{Hb})$ were immediately determined using an $\mathrm{Hb}$ photometer (HemoCue AB, Angelholm, Sweden). The remaining blood was centrifuged and separated into plasma (stored at $-80^{\circ} \mathrm{C}$ ), buffy coat, and erythrocyte pellet, stored in guanidine hydrochloride (G$\mathrm{HCl})$ at $4^{\circ} \mathrm{C}$

Parasitology. Plasmodium species and counts (number of parasites per 200 leukocytes) were analyzed by microscopy and recorded. A parasite negative slide was one on which 2,000 leukocytes were observed and no parasites seen (i.e., 10 fields). Duplicate readings were made for $20 \%$ of smears. The following age-stratified leukocyte counts were used to calculate parasites per microliter of blood: $<4$ years, 8.6 x $10^{3}$ leukocytes/(xL; 5-9 years, $7.8 \times 10^{3}$ leukocytes/(xL; > 10 years, $7.7 \times 10^{3}$ leukocytes/jxL (M. Bruce, unpublished data).

Laboratory methods. Plasma Hp levels were determined by ELISA. ${ }^{22}$ Hypohaptoglobinemia was defined as $\mathrm{Hp}<0.18$ $\mathrm{mg} / \mathrm{mL}{ }^{23}$ Commercial ELISA kits were used to measure levels of CRP (American Laboratory Products, Windham, NH). An APR was defined as CRP > $10\left(\mathrm{xg} / \mathrm{mL}\right.$. ${ }^{1}$ Levels of $\mathrm{o}_{1^{-}}$ antitrypsin were determined using a commercial ELISA kit (American Laboratory Products). $\mathrm{o}_{1}$-Antitrypsin levels $>4$ $\mathrm{mg} / \mathrm{mL}$ are consistent with an APR. ${ }^{2}$ Albumin concentrations were determined using bromocresol green reagent (Abbott Laboratories, Maidenhead, UK) and reading optical density at $630 \mathrm{~nm}$. Low albumin was defined as $<35 \mathrm{mg} / \mathrm{mL}^{23}$

Statistical analysis. Differences in APP concentrations between the 2 years were assessed using a Wilcoxon signed rank test. Within each year, the frequencies of categorical variables by splenomegaly were assessed by $\mathbf{x}^{2}$ tests or Fisher exact tests and continuous variables by Mann-Whitney $U$ tests or analysis of variance. Linear models were used to examine the effect variables of interest on APP levels: this included a subject random effect to allow for the correlation between the repeated measures contributed by each child in CRP and albumin analysis. ${ }^{24}$ This model does not require equally spaced or equal numbers of APP observations per child. ${ }^{25}$ The fitted model predicts the mean APP level for the population while controlling for statistically relevant variables.

Data considerations. Because CRP levels showed considerable heteroscedasticity (non-constancy of the variance), the levels were $\log$-transformed $[\log (\mathrm{CRP}+0.015)]$ before analysis by examining profile likelihoods. ${ }^{26}$ Plasmodium densities were transformed by $\log ($ Plasmodium spp. +1$)$, in the mixed model analyses to reduce the skewness but leaving the zero values unchanged.

Details of regression analysis. The linear models were developed using a stepwise procedure with Akaike Information Criterion (AIC) as the criterion of goodness of fit on a dataset, which omitted all subjects for whom any data were missing. The full model examined the effect of sex, age, splenomegaly, $\mathrm{Hb}$, and Plasmodium density temperature, together with a quadratic term for $\mathrm{Hb}, \mathrm{a}^{+}$-thalassemia genotype, Hp genotype, SAO, G6PD deficiency, ABO blood group, and interactions between variables. The final model was refitted to a dataset excluding only those subjects with missing data for the variables that remained in the model, and variables with $P>0.05$ removed. After excluding missing val- ues, 832 observations contributed to the final analysis. $P$ values reported are unadjusted.

SPSS (for Windows Rel 13.0. 2004; SPSS, Chicago, IL) was used for the analysis, with the exception of the CRP, albumin, and $\mathrm{o}_{1}$-antitrypsin linear models, which were developed in $\mathrm{R}$ 2.0.1. ${ }^{27}$

\section{RESULTS}

Characteristics of children. Data were collected from 546 children during two cross-sectional surveys that took place during November to December 1999 and 2000. APP levels were determined in 394 samples from 1999 and 466 samples in 2000 (343 pairs). The data differed from the main cohort with respect to age in 1999 only $(P<0.001)$. The mean $(\mathrm{SE})$ age of the original cohort was $8.58(0.16)$ years compared with the subsample, which had an older mean age of $9.78(0.15)$ years. This was because of a smaller volume of blood collected from some younger children, which limited the number of laboratory analyses.

Table 1 shows age, parasitologic, and APP data for the total population stratified by splenomegaly. There was no significant difference in variables between the 2 years; therefore, presented data was pooled. The proportion of children having an APR (CRP > $10(\mathrm{xg} / \mathrm{mL})$ was low $(8.2 \%)$, despite the fact that $63.5 \%$ of children had detectable parasitemia with any species of Plasmodium. The prevalence of splenomegaly was $21.9 \%$ in this population. Children with splenomegaly had significantly higher prevalences of Plasmodium and higher parasite densities compared with children with normal spleens $(P<0.05)$. Children with splenomegaly also had higher prevalences of CRP concentrations consistent with an APR $(P<0.001)$, together with higher levels of CRP $(P<$ $0.001)$ and lower levels of $\mathrm{Hp}(P<0.01)$ and albumin $(P<$ 0.01 ), compared with children with normal spleens (Table 1).

Multivariate analysis. Linear models were used to examine the effect of a large number of variables on CRP levels. The resulting fitted model predicts the median CRP level and 95\% confidence intervals (CIs) for the population, controlling for relevant variables. Although all children present in the surveys appeared healthy, for the purpose of analysis, the few children with a temperature $>37.5^{\circ} \mathrm{C}$ plus a parasitemia $>10,000$ parasites/jxL $(N=8)$ were excluded. Median CRP concentrations in these "symptomatic" children were $7.1 \mathrm{(xg} /$ $\mathrm{mL}$ [range, 1.4-36 (xg/mL]. The overall CRP level in this population after controlling for relevant variables was $1.45(\mathrm{xg} / \mathrm{mL}(95 \% \mathrm{CI}, 1.24,1.73)$. The model predicts that CRP levels decrease with age (coefficient $=-0.13 ; 95 \% \mathrm{CI}$, $-0.19,-0.07 ; P<0.001$ ) and increasing Hb levels (coefficient $=-0.17 ; 95 \% \mathrm{CI},-0.22,-0.11 ; P<0.001)$. CRP levels increased with increasing parasitemia (coefficient $=0.26 ; 95 \%$ CI, 0.2, 0.32; $P<0.001$ ) but remained $<3.5$ (xg/mL (Figure 1$)$. CRP concentrations were also elevated in children with fever (coefficient $=-0.55 ; 95 \% \mathrm{CI}, 0.26,0.84 ; P<0.001)$ and splenomegaly $($ coefficient $=1.43 ; 95 \% \mathrm{CI}, 0.81,2.05 ; P<$ 0.001). An interaction was found between age and splenomegaly. The decrease of CRP with age was less evident in those with normal spleens (coefficient $=0.11 ; 95 \% \mathrm{CI}, 0.04$, $0.17 ; P=0.002$ ) compared with those with splenomegaly.

The overall concentration of $o_{1}$-antitrypsin in the children was $3.02 \mathrm{mg} / \mathrm{mL}(95 \% \mathrm{CI}, 2.89,3.15)$ after adjusting for age (coefficient $=-0.05 ; 95 \% \mathrm{CI},-0.09,-0.1 ; P=0.01)$, para- 
TABLE 1

Distribution of age, parasitology, and acute phase proteins according to splenomegaly

\begin{tabular}{|c|c|c|c|c|}
\hline & \multirow[b]{2}{*}{ All children $(N=887)$} & \multicolumn{2}{|c|}{ Spleen size* } & \multirow[b]{2}{*}{$P$} \\
\hline & & Normal $(N=689)$ & Splenomegaly $(N=193)$ & \\
\hline \multicolumn{5}{|l|}{ Age (years) } \\
\hline $1-4$ & $74(8.3)$ & $51(7.4)$ & $22(11.4)$ & $<0.01$ \\
\hline $5-9$ & $276(31.1)$ & $183(26.6)$ & $91(47.2)$ & \\
\hline $10-17$ & $537(60.5)$ & $455(66.0)$ & $80(41.5)$ & \\
\hline Plasmodium spp. (\%) & $563(63.5)$ & $418(62.3)$ & $142(74.7)$ & $<0.05$ \\
\hline Density $\log _{10}$ value/|XLf & $2.66(0.03)$ & $2.57(0.04)$ & $2.93(0.7)$ & $<0.001$ \\
\hline Fever & $94(10.6)$ & 73 (10.6) & $21(11.1)$ & $>0.05$ \\
\hline \multicolumn{5}{|l|}{ Acute phase proteins } \\
\hline CRP $(\mid x g / m L)$ & $0.9[0.4-2.6]$ & $0.29[0.13-0.54]$ & $2.0[0.7-7.2]$ & $<0.001$ \\
\hline $\mathrm{CRP}>10 \mathrm{xg} / \mathrm{mL}$ & $72(8.2)$ & $38(5.5)$ & 34 (17.6) & $<0.001$ \\
\hline $\mathrm{Hp}(\mathrm{mg} / \mathrm{mL})$ & $0.26[0.11-0.49]$ & $0.29[0.13-0.54]$ & $0.16[0.07-0.33]$ & $<0.01$ \\
\hline$a_{1}$-Antitrypsin $(\mathrm{mg} / \mathrm{mL})$ & $3.1(0.17)$ & $3.07(0.22)$ & $3.3(0.11)$ & $>0.05$ \\
\hline Albumin $(\mathrm{mg} / \mathrm{mL})$ & $45.5(0.27)$ & $45.9(0.31)$ & $44(0.57)$ & $<0.01$ \\
\hline
\end{tabular}

Categorical values are $N(\%)$, continuous variables are mean (SE) or median [IQR]. Discrepancies in percentages are caused by missing values or rounding.

An acute phase response is defined as CRP $>10 \mathrm{jxg} / \mathrm{mL}$.

* Missing spleen data $N=5$.

t Density of positive slides.

$\$$ Data from 404 children in 1999 only (splenomegaly, $N=94$ ).

CRP, C-reactive protein; Hp, haptoglobin.

sitemia (coefficient $=-0.13 ; 95 \% \mathrm{CI}, 0.05,0.21 ; P=0.002$ ), and splenomegaly (coefficient $=0.44 ; 95 \% \mathrm{CI}, 0.17,0.71$; $P=0.002)$. The overall concentration of albumin in these children was $45.35 \mathrm{mg} / \mathrm{mL}(95 \% \mathrm{CI}, 44.77,45.9)$ after adjusting for significant confounders. Albumin concentration increased with age (coefficient $=0.53 ; 95 \% \mathrm{CI}, 0.35,0.7 ; P<$ 0.001 ) and increasing $\mathrm{Hb}$ concentration (coefficient $=0.54$; $95 \%$ CI, 0.19, 0.89; $P=0.002$ ). Albumin was not significantly associated with parasitemia.

There was no significant association of $\mathrm{a}^{+}$-thalassemia genotype, Hp genotype, SAO, G6PD deficiency, or ABO blood group with either CRP, $o_{1}$-antitrypsin, or albumin concentrations in this population of asymptomatic children from PNG.

\section{DISCUSSION}

The Amele region of PNG experiences intense, year round transmission of malaria. ${ }^{16}$ Episodes of clinical malaria associated with fever, splenomegaly, and parasitemia above the fever threshold of 1,000 parasites/(JLL occur, particularly in chil-

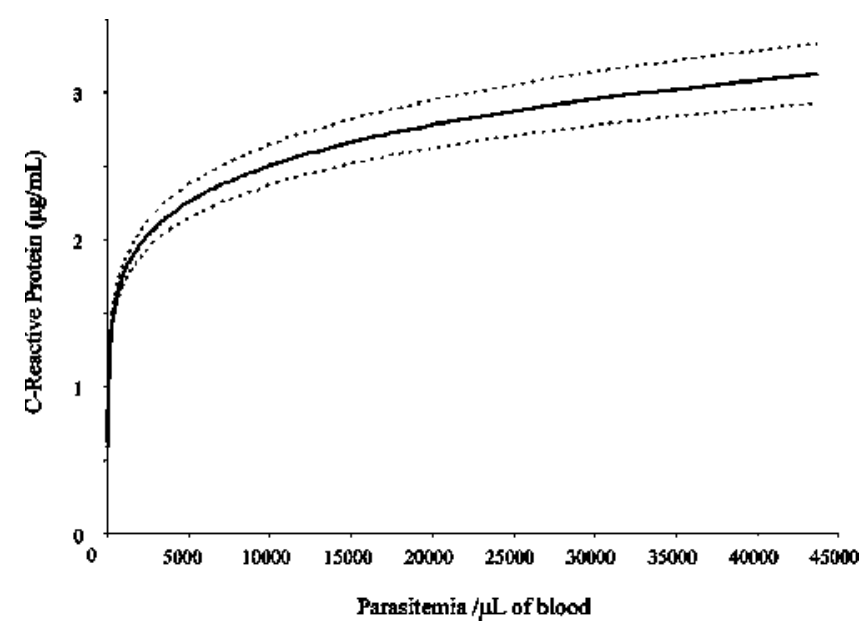

FIGURE 1. Predicted C R P levels in asymptomatic children in relation to parasitemia. dren $<5$ years. ${ }^{14}$ A positive smear in a cross-sectional survey points to an infection of at least 40 parasites/|xL of blood, although children in the Amele are infected with parasite densities below this detection limit, as shown by PCR and re-emergence of particular parasite genotypes. ${ }^{28},{ }^{29}$ Longitudinal observation of semi-immune children ( $>4$ years) in the Amele show that they harbor chronic, asymptomatic malaria infections with all Plasmodium spp. ${ }^{13}$ Children who are parasite negative 1 day have a high probability of being positive the next day because $P$. falciparum infections in this population are quite synchronous. ${ }^{30}$ Indeed, cumulative Plasmodium prevalence has been shown to be $>98.5 \%$ in children from the Amele region. ${ }^{30}$

Given the burden of chronic asymptomatic malaria infection, as well as clinical malaria, children living in Amele could be expected to have a chronic inflammatory response to continued and prolonged exposure to Plasmodium infections. It is therefore surprising that $<10 \%$ of children in both years had evidence of an APR, and median levels of CRP were only 1.49 (jug/mL (95\% CI, 1.25, 1.78). This does not vary considerably from the serum concentration of CRP in the healthy human population, which has a median value of $0.8(\mathrm{xg} / \mathrm{mL}$ (interquartile range, $0.3-1.7 \mathrm{xg} / \mathrm{mL})$ and is $<10(\mathrm{xg} / \mathrm{mL}$ in $99 \%$ of normal processes. ${ }^{31}{ }^{32}$ These PNG data contrast with higher APR prevalences found in Africa; we have also found APR prevalences as high as $81 \%$ in Gabonese asymptomatic children (temperature $<37.5^{\circ} \mathrm{C}$ in the absence or presence of asexual parasitemia; F.J.I. Fowkes, unpublished observation). ${ }^{6-8}$

During a febrile episode of malaria, CRP levels peak 1-2 days after an inflammatory stimulus, and elevated CRP levels may increase by $30,000 \%$ and return to baseline 7-14 days later. ${ }^{1}$ A previous study in asymptomatic children from The Gambia showed that the median CRP concentration in children with a parasitemia > 5,000 parasites/(JLL was $34.5(\mathrm{xg} / \mathrm{mL}$ $\left(95 \%\right.$ CI, 29.1, 40.9). ${ }^{7}$ In our study, multivariate analysis showed that, in chronically infected Amele children with no evidence of clinical malaria, CRP levels do not vary significantly among children with high density parasitemia (> 10,000 parasites/(xL in the absence of fever) and remain 
< 3.5 (xg/mL. Data from children with mild malaria (fever plus parasitemia > 10,000/(xL) in this area show that the median CRP concentration was 116.4 (xg/mL (95\% CI, 91.7, 147.9: F.J.I. Fowkes, unpublished observations). ${ }^{33}$ It would seem that high-density parasitemia alone cannot stimulate an APR.

Children in the Amele study could be differentiated on the basis of whether they had splenomegaly, because this is particularly indicative of recent high-density parasitemia (> 10,000 parasites/jxL) in PNG. ${ }^{34}$ Asymptomatic children with splenomegaly had higher prevalences and densities of Plasmodium spp. and higher levels of CRP. The higher levels of CRP detected most likely represent the decline of CRP after an acute episode of malaria, where an individual most likely experienced an APR ${ }^{6,8}$ CRP levels decreased with age in children with splenomegaly. Older children will have the benefit of a more effective acquired immune response so they may experience a reduction in the level of inflammatory response.

Children with splenomegaly also had lower levels of $\mathrm{Hp}$. This most likely represents clearance of the $\mathrm{Hp}-\mathrm{Hb}$ complex during the mass hemolysis seen in heavy malaria infection. ${ }^{35}$ We have previously reported that concentrations of $\mathrm{Hp}$ are associated with both Hp genotype and $\mathrm{a}^{+}$-thalassemia genotype. ${ }^{15}$ There was no significant association with the APP concentrations reported here and host genotype. Therefore, previous differences in $\mathrm{Hp}$ levels with respect to $\mathrm{Hp}$ and $\mathrm{a}^{+}-$ thalassemia genotype were most likely caused by differences in Hp clearance rather than IL-6-dependent production.

Children living in the Amele experience chronic year round infections. We showed they modulate inflammation associated with malaria infection as evidenced by the absence of an APR. The mechanism modulating the balance between infection and disease in these children warrants further study.

Received May 24, 2006. Accepted for publication October 12, 2006.

Financial support: This work was funded by the Wellcome Trust and the European Community (E.C. Grant IC18-CT98-0359).

Authors' addresses: Heather Imrie and Peter Medawar, Building for Pathogen Research, Department of Zoology, South Parks Road, University of Oxford, Oxford OX1 3SY, UK, E-mail: heather imrie@medawar.ox.ac.uk. Freya J. I. Fowkes and K. P. Day, Department of Medical Parasitology, New York University School of Medicine, 341 East 25th Street, New York, NY 10010, Telephone: 212263-6800, Fax: 212-263-8116, E-mail: freya.fowkes@med.nyu.edu and Karen.day@med.nyu.edu. Pascal Michon, and Livingstone Tavul, Papua New Guinea Institute of Medical Research, PO Box 378, Madang 511, Papua New Guinea, Telephone: 675-852-2909, Fax: 675852-3289, E-mail: pmichon@datec.net.pg and livingstone.tavul® pngimr.org.pg. John C. Reeder, Papua New Guinea Institute of Medical Research, PO Box 60, Goroka, EHP 441, Papua New Guinea, E-mail: john.reeder@pngimr.org.pg.

\section{REFERENCES}

1. Gabay C, Kushner I, 1999. Acute-phase proteins and other systemic responses to inflammation. N Engl J Med 340: 448-154.

2. Koj A, 1985. Definition and classification of acute phase proteins. Gordon A, Koj A, eds. The Acute Phase Response to Injury and Infection. Amsterdam: Elsevier Science Publishers, 139144.

3. Karunaweera ND, Grau GE, Gamage P, Carter R, Mendis KN, 1992. Dynamics of fever and serum levels of tumor necrosis factor are closely associated during clinical paroxysms in Plasmodium vivax malaria. Proc Natl Acad Sci USA 89:3200-3203.

4. Kwiatkowski D, Cannon JG, Manogue KR, Cerami A, Dinarello
CA, Greenwood BM, 1989. Tumour necrosis factor production in falciparum malaria and its association with schizont rupture. Clin Exp Immunol 77: 361-366.

5. Jakobsen PH, McKay V, N'Jie R, Olaleye BO, D'Alessandro U, Zhang GH, Eggelte TA, Koch C, Greenwood BM, 1998. Decreased antitoxic activities among children with clinical episodes of malaria. Infect Immun 66: 1654-1659.

6. Hurt N, Smith T, Teuscher T, Tanner M, 1994. Do high levels of $\mathrm{C}$-reactive protein in Tanzanian children indicate malaria morbidity. Clin Diagn Lab Immunol 1: 437-444.

7. McGuire W, D'Alessandro U, Olaleye BO, Thomson MC, Langerock P, Greenwood BM, Kwiatkowski D, 1996. Creactive protein and haptoglobin in the evaluation of a community-based malaria control programme. Trans $R$ Soc Trop Med Hyg 90: 10-14.

8. Hurt N, Smith T, Tanner M, Mwankusye S, Bordmann G, Weiss NA, Teuscher T, 1994. Evaluation of C-reactive protein and haptoglobin as malaria episode markers in an area of high transmission in Africa. Trans R Soc Trop Med Hyg 88: 182186.

9. Naik P, Voller A, 1984. Serum C-reactive protein levels and falciparum malaria. Trans $R$ Soc Trop Med Hyg 78: 812-813.

10. Ree GH, 1971. C-reactive protein in Gambian Africans with special reference to $P$. falciparum malaria. Trans $R$ Soc Trop Med Hyg 65: 574-580.

11. Chagnon A, Yao N, Carli P, Paris JF, Marlier S, Pierre C, Bussiere H, 1992. C-reactive protein. Presse Med 21: 217-218.

12. Verhoef H, West CE, Ndeto P, Burema J, Beguin Y, Kok FJ, 2001. Serum transferrin receptor concentration indicates increased erythropoiesis in Kenyan children with asymptomatic malaria. Am J Clin Nutr 74: 767-775.

13. Bruce MC, Donnelly CA, Alpers MP, Galinski MR, Barnwell JW, Walliker D, Day KP, 2000. Cross-species interactions between malaria parasites in humans. Science 287: 845-848.

14. Cox MJ, Kum DE, Tavul L, Narara A, Raiko A, Baisor M, Alpers MP, Medley GF, Day KP, 1994. Dynamics of malaria parasitemia associated with febrile illness in children from a rural area of Madang, Papua New Guinea. Trans $R$ Soc Trop Med Hyg 88: 191-197.

15. Imrie H, Fowkes FJ, Michon P, Tavul L, Hume JC, Piper KP, Reeder JC, Day KP, 2006. Haptoglobin levels are associated with haptoglobin genotype and $\{\text { alpha }\}^{+}$-thalassemia in a malaria-endemic area. Am J Trop Med Hyg 74: 965-971.

16. Cattani JA, Tulloch JL, Vrbova H, Jolley D, Gibson FD, Moir JS, Heywood PF, Alpers MP, Stevenson A, Clancy R, 1986. The epidemiology of malaria in a population surrounding Madang, Papua New Guinea. Am J Trop Med Hyg 35: 3-15.

17. Burkot TR, Graves PM, Cattan JA, Wirtz RA, Gibson FD, 1987. The efficiency of sporozoite transmission in the human malarias, Plasmodium falciparum and P. vivax. Bull World Health Organ 65: 375-380.

18. Flint J, Hill AV, Bowden DK, Oppenheimer SJ, Sill PR, Serjeantson SW, Bana-Koiri J, Bhatia K, Alpers MP, Boyce AJ, Weatherall DJ, Clegg JB, 1986. High frequencies of alphathalassaemia are the result of natural selection by malaria. Nature 321: 744-750.

19. Brabin L, Brabin BJ, 1990. Malaria and glucose 6-phosphate dehydrogenase deficiency in populations with high and low spleen rates in Madang, Papua New Guinea. Hum Hered 40: $15-21$.

20. O’Donnell A, Allen SJ, Mgone CS, Martinson JJ, Clegg JB, Weatherall DJ, 1998. Red cell morphology and malaria anaemia in children with Southeast-Asian ovalocytosis band 3 in Papua New Guinea. Br J Haematol 101: 407-412.

21. Imrie H, Fowkes F, Michon P, Tavul L, Hume J, Piper K, Day KP, 2006. Haptoglobin levels are associated with haptoglobin genotype and alpha ${ }^{+}$-thalassemia in a malaria endemic area. Am J Trop Med Hyg. 74: 965-971.

22. Fowkes FJ, Imrie H, Migot-Nabias F, Michon P, Justice A, Deloron P, Luty AJ, Day KP, 2006. Association of haptoglobin levels with age, parasite density, and haptoglobin genotype in a malaria-endemic area of Gabon. Am J Trop Med Hyg 74: 26-30.

23. Rosales FJ, Topping JD, Smith JE, Shankar AH, Ross AC, 2000. Relation of serum retinol to acute phase proteins and malarial 
morbidity in Papua New Guinea children. Am J Clin Nutr 71: $1582-1588$.

24. Zeger S, Liang K, Diggle P, 1996. Analysis of Longitudinal Data. Oxford, UK: Oxford University Press.

25. Manor O, Kark J, 1996. A comparitive study of four methods for analysis of repeated measures data. Stat Med 15: 114

26. Venables W, Ripley B, 2002. Modern Applied Statistics with S. New York: Springer-Verlag.

27. R Development Core Team, 2005. R: A Language and Environment for Statistical Computing. Vienna, Austria: R Foundation for Statistical Computing.

28. Bruce MC, Day KP, 2002. Cross-species regulation of malaria parasitemia in the human host. Curr Opin Microbiol 5: 431437.

29. Bruce MC, Galinski MR, Barnwell JW, Donnelly CA, Walmsley M, Alpers MP, Walliker D, Day KP, 2000. Genetic diversity and dynamics of Plasmodium falciparum and $P$. vivax populations in multiply infected children with asymptomatic malaria infections in Papua New Guinea. Parasitology 121: 257-272.

30. Bruce MC, Donnelly CA, Packer M, Lagog M, Gibson N, Narara
A, Walliker D, Alpers MP, Day KP, 2000. Age- and speciesspecific duration of infection in asymptomatic malaria infections in Papua New Guinea. Parasitology 121: 247-256.

31. Pepys MB, Baltz ML, 1983. Acute phase proteins with special reference to $\mathrm{C}$-reactive protein and related proteins (pentaxins) and serum amyloid A protein. Adv Immunol 34: 141-212.

32. Vigushin DM, Pepys MB, Hawkins PN, 1993. Metabolic and scintigraphic studies of radioiodinated human C-reactive protein in health and disease. J Clin Invest 91: 1351-1357.

33. Allen SJ, O'Donnell A, Alexander ND, Alpers MP, Peto TE, Clegg JB, Weatherall DJ, 1997. alpha+-Thalassemia protects children against disease caused by other infections as well as malaria. Proc Natl Acad Sci USA 94: 14736-14741.

34. Genton B, Smith T, Baea K, Narara A, al-Yaman F, Beck HP, Hii J, Alpers M, 1994. Malaria: how useful are clinical criteria for improving the diagnosis in a highly endemic area? Trans $R$ Soc Trop Med Hyg 88: 537-541.

35. Lim SK, Ferraro B, Moore K, Halliwell B, 2001. Role of haptoglobin in free hemoglobin metabolism. Redox Rep 6: 219-227. 